\title{
PERANCANGAN APLIKASI PENAGIHAN MEMBER PARKING BERBASIS JAVA PADA PERTANI GRAHA GABAH
}

\author{
Dwi Rendragraha ${ }^{1}$, Syamsiah $^{2}$, Noor Komari Pratiwi ${ }^{3}$ \\ ${ }^{1,2,3}$ Universitas Indraprasta PGRI \\ Jl. Raya Tengah No. 80, Kel. Gedong, Kec. Pasar Rebo, Jakarta Timur 13760, Jakarta \\ 1. rendradizzy@gmail.com, ${ }^{2}$ ncham.unindra08@gmail.com, ${ }^{3}$ noorkomaripratiwi01@ @mail.com
}

\begin{abstract}
ABSTRAK
PT.Pertani merupakan badan usaha milik negara yang mempunyai anak perusahaan bernama Pertani Properti. Pertani Properti dipercayakan untuk mengelola lahan parking yang ada di Jalan Raya Pasar Minggu, Pertani No.1 RT/RW 008/003. Pendataan member parking masih dilakukan dengan menggunakan microsoft office, kemudian dicetak menjadi laporan. Hal tersebut menyebabkan kemungkinan kehilangan data. Tujuan dari penelitian ini adalah untuk merancang dan menerapkan suatu aplikasi penagihan member parking yang diharapkan menjadi solusi terhadap masalah tersebut sehingga pendataan dan penyimpanan data tersimpan secara komputerisasi. Metode penelitian yang digunakan adalah penelitian kualitatif dengan metode studi lapangan. Metode pengambilan data yaitu melalui pengamatan langsung, wawancara dengan pihak terkait, serta melakukan dokumentasi untuk mendapatkan informasi yang dibutuhkan. Bagaimana sistem dikembangkan adalah dengan menggunakan metode Waterfall. Sebagai hasil dari penelitian ini adalah adanya penyimpanan data menggunakan satu set aplikasi yang ditulis dalam bahasa pemrograman Java NetBeans dan database MySQL. Perancangan yang digunakan untuk sistem ini dengan tools yaitu Diagram Aliran Data (DAD) Konteks, Diagram Nol dan Diagram Rinci. Dapat disimpulkan, sistem ini dapat membantu dan mempermudah staf administrasi dalam melakukan proses penagihan member parking di lokasi Pertani Graha Gabah.
\end{abstract}

Kata Kunci: Sistem Aplikasi, Penagihan, Member parking, Java, MySQL

\begin{abstract}
PT. Pertani is a state-owned enterprise which has a subsidiary called Pertani Properti. Pertani Properti is entrusted to manage the parking area on Jalan. Raya Pasar Minggu, Pertani No.1 RT/RW 008/003. Member parking data collection is still done using Microsoft Office, then printed into a report. This causes possible data loss. The purpose of this study is to design and implement a member parking billing application which is expected to be a solution to this problem so that data collection and data storage are stored computerized. Research methodology that used to application system for parking members in the method of data retrieval is observation, documentation studies to get information that needed. System development method that used is waterfall methods. Study results are the existence of an application device that made using programming language and MySQL database. This application is built using system design tools Data Flow Diagram (DFD) context, Zero Diagram, and Level Diagram, so that can help parking administration staff to process parking members in Pertani Graha Gabah.
\end{abstract}

Key Word: Applilcation System, Billing, Parking Member, Java, MySQL

\section{PENDAHULUAN}

Di era globalisasi yang semakin maju, mobilisasi masyarakat begitu tinggi. Kendaraan sangat dibutuhkan dalam mendukung kehidupan sehari-hari. Banyak masyarakat selaku pemilik kendaraan, khususnya mobil, memiliki kendala terkait lahan untuk menyimpan kendaraannya. Mereka memanfaatkan ruang pejalan kaki sebagai lahan parkir untuk kendaraannya. Hal ini bertentangan dengan Peraturan Lalu Lintas No 5 DKI Jakarta 2014 mengatur bahwa setiap orang atau badan usaha pemilik kendaraan bermotor dilarang menyimpan kendaraan bermotor di ruang milik jalan dan wajib memiliki atau menguasai garasi (Peraturan Daerah Ibu kota Jakarta, 2014).

Warga di Jalan Pertani Raya, Jalan Raya Pasar Minggu, Kota Administrasi Jakarta Selatan banyak yang mempuyai mobil namun tidak mempunyai garasi, Dengan luasnya lahan lapang atau gedung yang tidak terpakai pada PT. Pertani, pihak Pertani Properti sebagai pengelola parkir mengajukan saran kepada pihak PT. Pertani agar tanah atau lahan lapang yang tidak digunakan dapat dipergunakan sebagai tempat parkir kendaraan warga. 
Dengan begitu, warga yang ingin menitipkan mobilnya harus membayar biaya sewa bulanan kepada Pertani Properti.

Oleh karena itu, dibutuhkan suatu perancangan sistem aplikasi penagihan member parking pada Pertani Graha Gabah agar pengolahan data menjadi lebih berguna dan cepat serta terkomputerisasi dengan baik. Selain itu, data menjadi lebih valid dan bisa langsung diolah ke dalam database. Diharapkan perancangan sistem aplikasi penagihan member parking ini dapat mempercepat proses pembuatan laporan yang berkaitan dengan data penagihan member parking sesuai dengan kebutuhan.

Penagihan merupakan serangkaian tindakan yang dilakukan pihak penagih terhadap konsumen agar konsumen melunasi utang dan biaya penagihan yang telah disepakati dalam akad. Dalam tindakan penagihan, Teguran dan peringatan akan langsung ditagih oleh pemungut, sekaligus ditagihkan, diberikan surat, dan mengusulkan pencegahan (Hidayat \& Cheisviyanny, 2013).

Perancangan adalah proses mendefinisikan apa yang dapat Anda lakukan dengan teknik yang berbeda, termasuk detail arsitektur dan komponen, dan deskripsi keterbatasan yang dialami dalam proses tersebut (Rizky, 2011).

Aplikasi adalah alat terapan yang memiliki fungsi tertentu dan terintegrasi sesuai dengan fungsinya (Sutabri, 2012).

Definisi parkir terbagi menjadi dua yaitu. Parkir di badan jalan dan parkir luar badan jalan. Parkir di badan jalan membutuhkan badan jalan untuk digunakan sebagai tempat parkir, misalnya parkir di depan toko tempat kendaraan berhenti di pinggir jalan. Sementara itu, parkir di luar badan jalan tidak memerlukan badan jalan untuk parkir, tetapi disediakan area khusus untuk parkir kendaraan. (Budiman \& Triono, 2016).

Berdasarkan penjelasan di atas, dirancanglah aplikasi penagihan member parking pada Pertani Graha Gabah berbasis java. Diharapkan sistem ini dapat membantu administrasi agar lebih tepat dan cepat dalam penagihan member parking, data yang tersimpan lebih aman dan kemudahan dalam membuat laporan.

Hal ini sesuai dengan hasil penelitian yang menyimpulkan bahwa dengan adanya sistem aplikasi berbasis java, pembuatan laporan akan menjadi lebih efektif dan efisien, serta dapat mempermudah staf admin dalam melakukan tugasnya (Ismunandar et al., 2021).

\section{METODE PENELITIAN}

Metode pengumpulan data yang dilakukan untuk mendapatkan data-data serta informasi untuk mendukung penyempurnaan hasil dari penelitian ini antara lain:

Metode Lapangan (Field Research)

a. Observasi (Pengamatan Langsung)

Penulis mempelajari dan mengamati sistem pengelolaan data member parking pada Pertani Graha Gabah serta keterkaitan antara subsistem satu dengan yang lainnya dengan meninjau tentang data yang ada pada lingkungan tersebut.

\section{b. Wawancara}

Wawancara merupakan suatu teknik pengumpulan data yang penulis lakukan dengan cara tanya jawab.

c. Studi Pustaka

Pengumpulan data dan informasi dari kutipan buku-buku, peraturan perundang-undangan, serta hasil laporan dan bahan lainnya yang berkaitan dengan penelitian ini

Metode penelitian ini menggunakan metode penelitian kualitatif. Kata kualitatif menitikberatkan pada proses dan makna yang belum teruji atau terukur secara akurat dalam hal kuantitas, kuantitas, intensitas, atau frekuensi (Ahmadi, 2014).

Langkah-langkah pengembangan sistem yang diterapkan pada perancangan ini menggunakan metode waterfall. Metode waterfall adalah model pengembangan sistem informasi yang sistematis dan berurutan. Metode waterfall memiliki lima fase: analisis dan definisi kebutuhan, desain sistem dan perangkat lunak, implementasi dan pengujian unit, integrasi dan pengujian sistem, serta operasi dan pemeliharaan (Sommerville, 2011) 
Java adalah pemrograman yang sangat populer karena banyaknya aplikasi yang dapat ditulis menggunakan bahasa ini, mulai dari komputer hingga smartphone. Bahasa pemrograman Java dimulai oleh James Gosling dan dikembangkan oleh Sun Microsystems, yang diluncurkan pada tahun 1995. Sun Microsystems kini telah diakuisisi oleh Oracle Corporation. Jika terbiasa dengan $\mathrm{C}$ dan $\mathrm{C}++$, maka dapat belajar Java dengan cepat (Enterprise, 2015).

MySQL merupakan basisdata yang menyatukan script PHP dengan perintah query dan escapt character yang sama dengan PHP (Sadeli, 2014).

Netbeans adalah IDE (Integrated Development Environment) open source yang dikembangkan dalam bahasa pemrograman Java. Netbeans memiliki berbagai pemrograman yang terintegrasi ke dalam perangkat lunak yang menyediakan pengembangan pemrograman GUI, editor teks, kompiler, dan juru bahasa (Westriningsih, 2012).

iReport adalah laporan perancangan visual yang dibangun pada JasperReport. Report adalah pelaporan atau desainer visual yang intuitif dan mudah digunakan untuk JasperReport, yang ditulis dalam Java (Kurniawan, H., Eri, M., \& Nur, 2011).

Diagram alur data adalah bentuk dari sistem untuk menggambarkan pembagian sistem ke modul yang lebih kecil. Salah satu keuntungan menggunakan data flow diagram (DAD) adalah akan memudahkan pengguna atau yang belum terbiasa dengan komputer untuk memahami sistem yang sedang dikerjakan (Ladjamudin, 2013).

\section{HASIL DAN PEMBAHASAN}

Berdasarkan dari hasil penelitian yang dilakukan oleh peneliti, maka dapat diketahui permasalahan yang terjadi pada proses penagihan member yaitu:

1. Staff administrasi melakukan beberapa kegiatan penagihan member masih dengan cara manual yaitu dengan menulis surat penagihan di form kertas atau dengan cara menghubungi via telepon.
2. Data yang tersimpan dalam kertas beresiko dalam keamanannya.

3. Pembuatan laporan penagihan member kurang efisien karena harus mengumpulkan data-data yang disimpan di kertas form kemudian di input ulang ke dalam Microsoft Excel.

Berdasarkan permasalahan-permasalahan yang telah dianalisa, peneliti memberikan alternatif penyelesaian masalah, diantaranya:

1. Sistem aplikasi penagihan member parking di Pertani Graha Gabah yang terkomputerisasi sehingga beberapa kegiatan yang berhubungan dengan penagihan member bulanan tidak dituliskan dikertas atau menggunakan excel melainkan dengan sistem komputer dan keakuratan data akan terjamin.

2. Membuat rancangan sistem yang memiliki database sebagai sistem penyimpanan dan pengolahan data sehingga dapat terjamin keamananya.

3. Dengan adanya Sistem aplikasi penagihan member parking admin menjadi lebih mudah dalam pembuatan laporan.

Merancang sistem pengolahan data yang terkomputerisasi sehingga data saling terintegrasi satu sama lainnya sehingga memudahkan dalam penyusunan laporan.

\section{Diagram Konteks Sistem yang Diusulkan} Berikut adalah gambaran sistem yang diusulkan untuk penagihan member parking pada Pertani Graha Gabah:

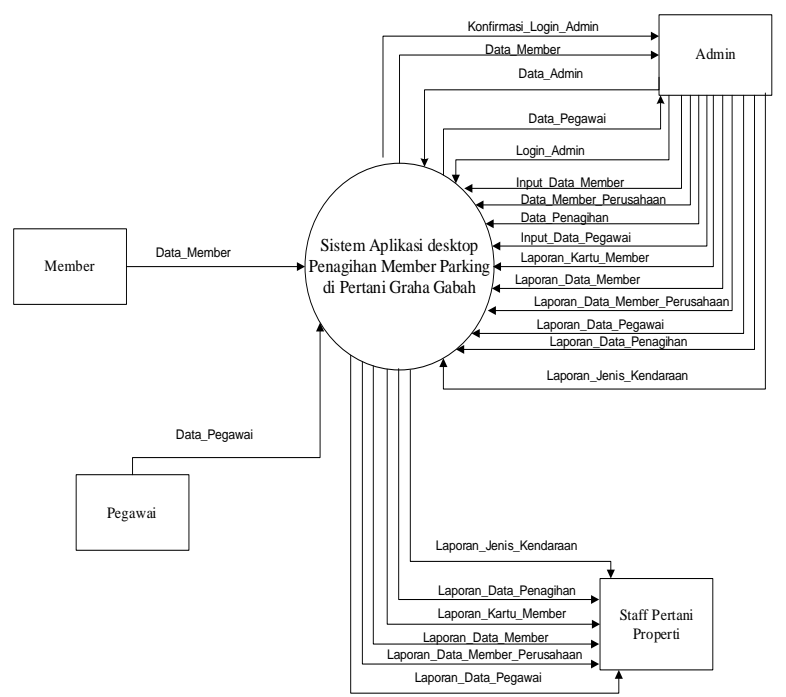

Gambar 1. Diagram Konteks Sistem 


\section{Diagaram Nol Sistem}

Diagram nol merupakan gambaran proses sistem berjalan pada sistem penagihan member parking yang menggambarkan tahaptahap proses dari diagram konteks, yaitu.

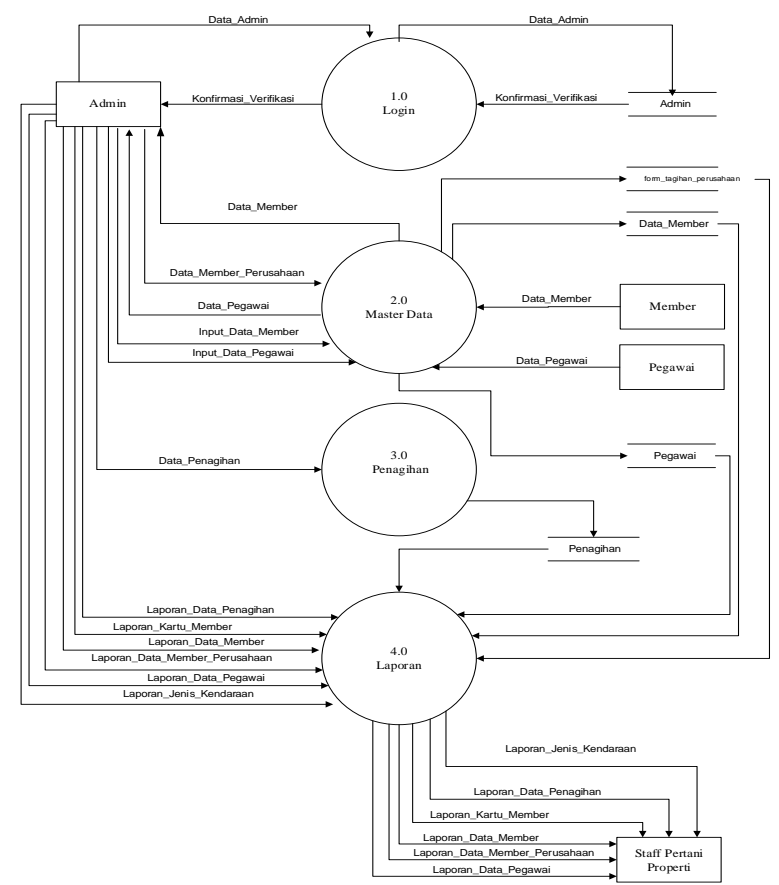

Gambar 2. Diagram Nol Sistem

\section{Entity Relationship Diagram (ERD)}

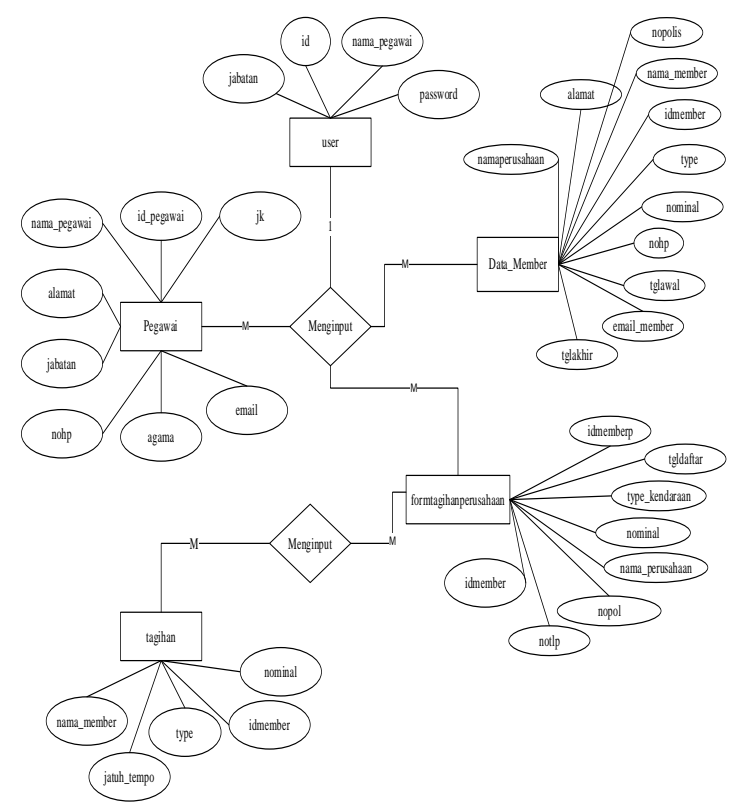

Gambar 3. ERD
Normalisasi Tahap Pertama (1NF)

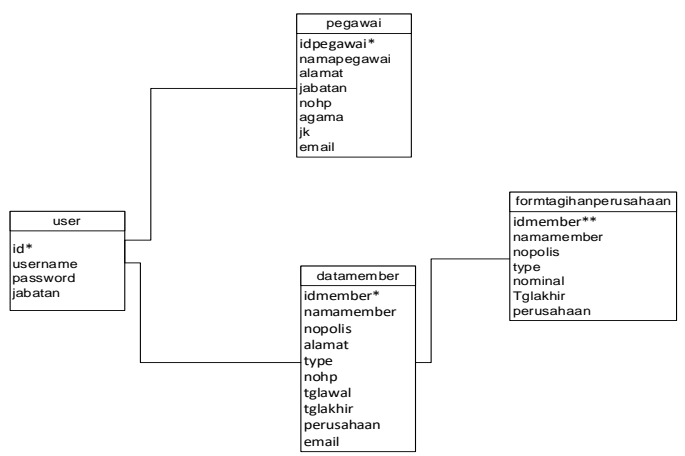

Gambar4. Normalisasi Tahap Pertama (1NF)

\section{Normalisasi Tahap Kedua (2NF)}

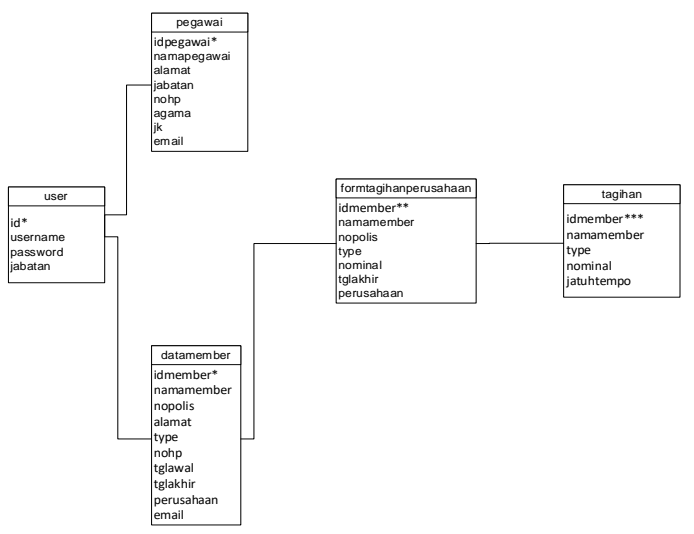

Gambar 5. Normalisasi Tahap Kedua (2NF)

Tampilan Menu Login

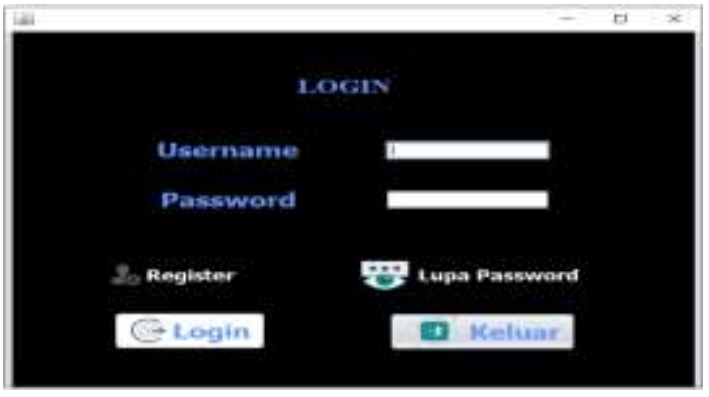

Gambar 6. Tampilan Menu Login

Pada tampilan menu login admin sebagai pengguna harus mengisi username dan password agar dapat masuk ke dalam program utama. Mencegah siapa pun dapat mengakses program ini. Oleh karena itu, form menu dijaga kerahasiaannya dengan baik lantaran ada menu login. 


\section{Tampilan Menu Home}

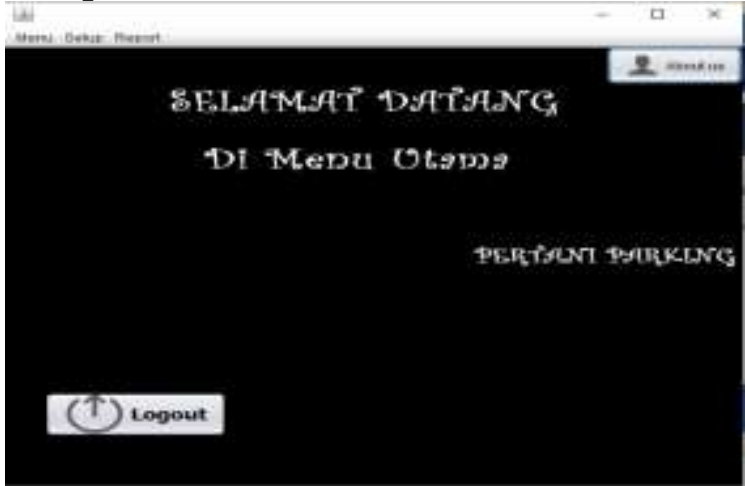

Gambar 7. Tampilan Menu

Pada tampilan menu home terdapat menu pada bar yaitu menu, setup dan report di dalam menu terdapat sub menu form pegawai, di dalam menu setup terdapat sub menu data member, data member perusahaan dan laporan data member. Didalam menu report terdapat sub menu cetak tagihan dan juga laporan data user sedangkan logout terdapat perintah yang membuat kita keluar dari menu utama.

\section{Tampilan Form Data Pegawai}

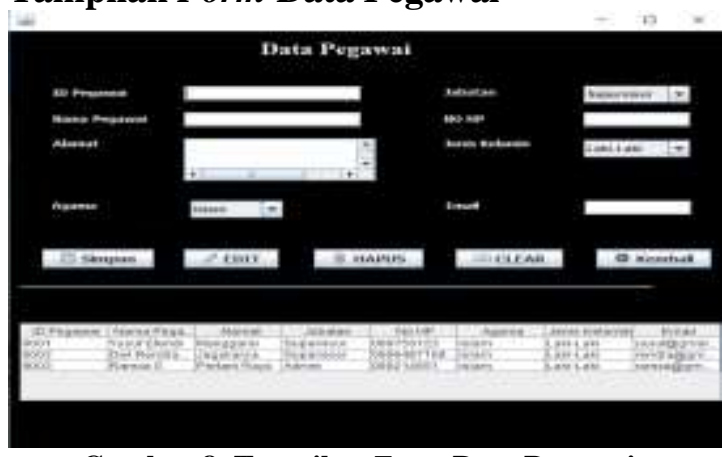

Gambar 8. Tampilan Form Data Pegawai

Form data pegawai digunakan untuk menginput data-data pegawai parking pada PT. Pertani Properti

\section{Tampilan Form Data Member}

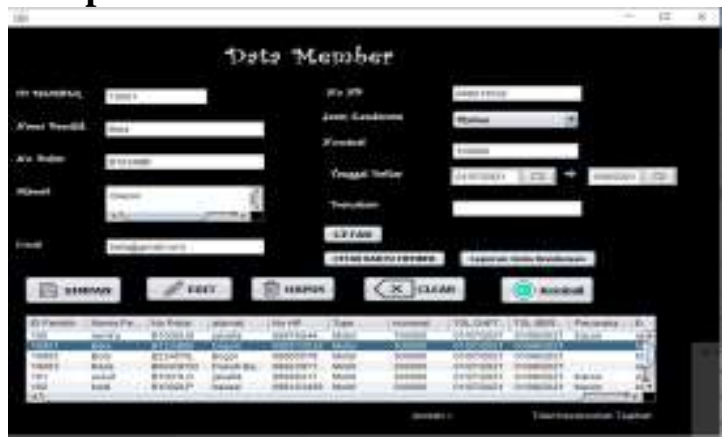

Gambar 9. Tampilan Form Data Member
Form data member digunakan untuk menginput data member yang ingin dititipkan kendaraanya di wilayah Pertani Graha Gabah

\section{Tampilan Form Data Member Perusahaan}

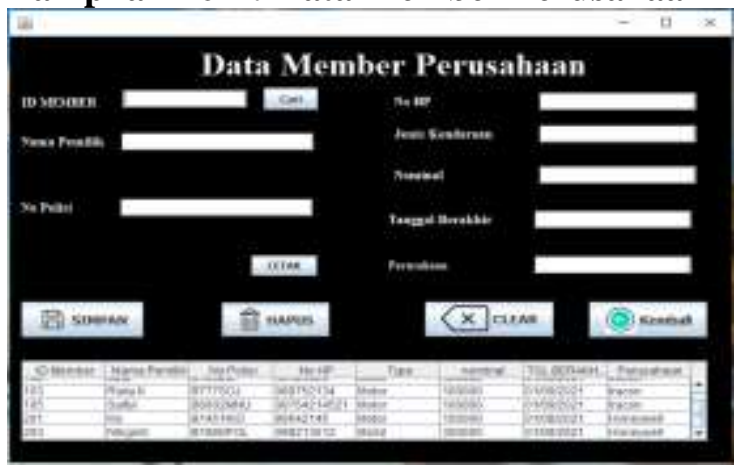

Gambar 10. Tampilan Form Data Member Perusahaan

Form data member perusahaan ini gunakan untuk menginput data member yang menitipkan kendaraannya melalui perusahaan.

\section{Tampilan Form Data User}

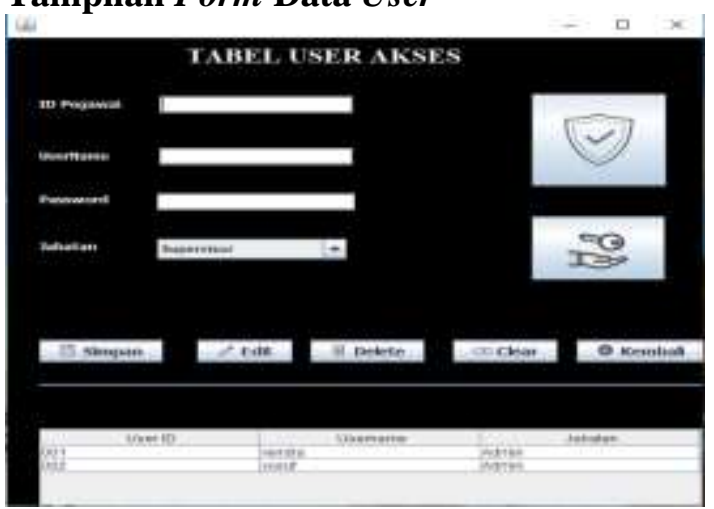

Gambar 11. Tampilan Form Data User

Form data user digunakan sebagai id login atau id pengguna untuk masuk ke menu utama.

\section{Tampilan Form Data Penagihan}

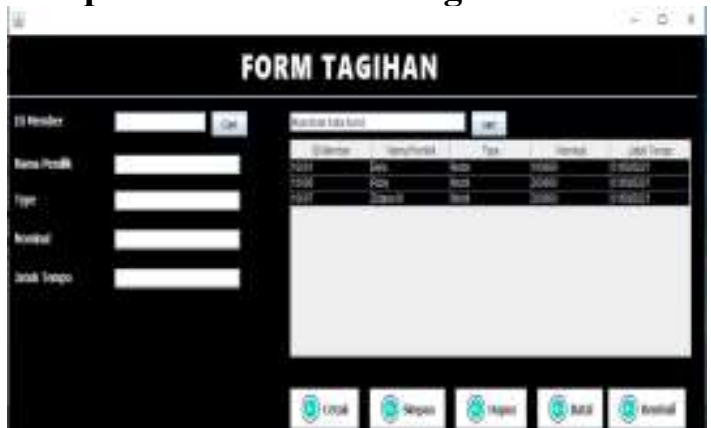

Gambar 12. Tampilan Form Data Penagihan 
Form tagihan digunakan untuk menginput data member yang akan dibuatkan surat penagihan.

\section{Tampilan Laporan Data Member}

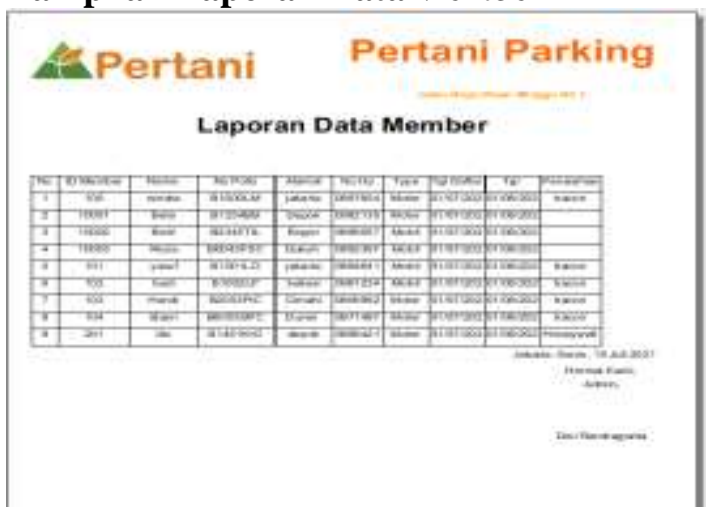

Gambar 13. Tampilan Laporan Data Member

Pada tampilan ini memperlihatkan laporan data member yang telah dicetak.

\section{Tampilan Laporan Tagihan Member} Perusahaan

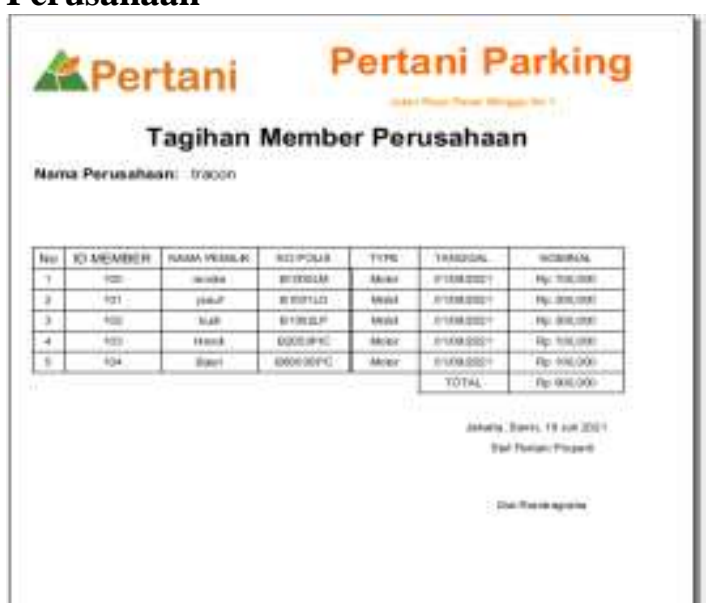

Gambar 14. Tampilan Laporan Tagihan Member Perusahaan

Pada tampilan ini menampilkan laporan member perusahaan yang telah dicetak.

\section{Tampilan Laporan Data Pegawai}

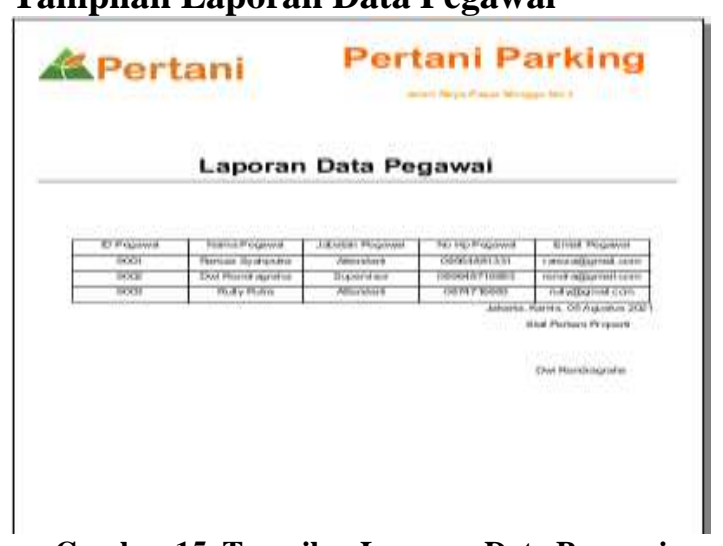

Gambar 15. Tampilan Laporan Data Pegawai
Pada tampilan ini menampilkan laporan data pegawai yang telah dicetak.

\section{Tampilan Laporan Jenis Kendaraan}

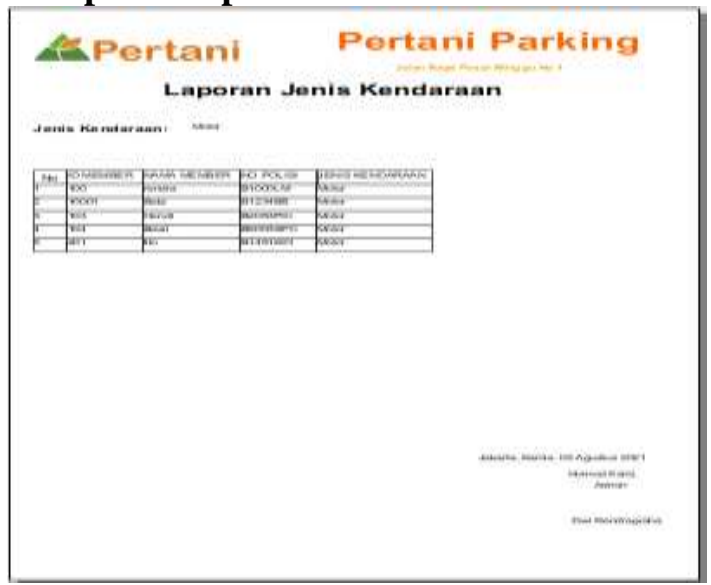

Gambar 16. Tampilan Laporan Jenis Kendaraan

Pada tampilan ini menampilkan laporan jenis kendaraan yang telah dicetak.

\section{Tampilan Laporan Kartu Member}

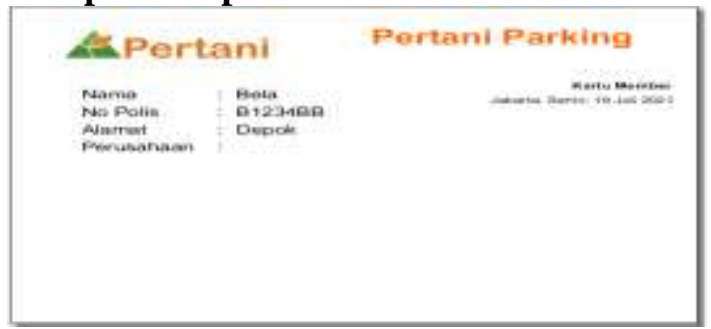

Gambar 17. Tampilan Laporan Kartu Member

Pada tampilan ini menampilkan laporan jenis kendaraan yang telah dicetak.

Tampilan Laporan Data Penagihan

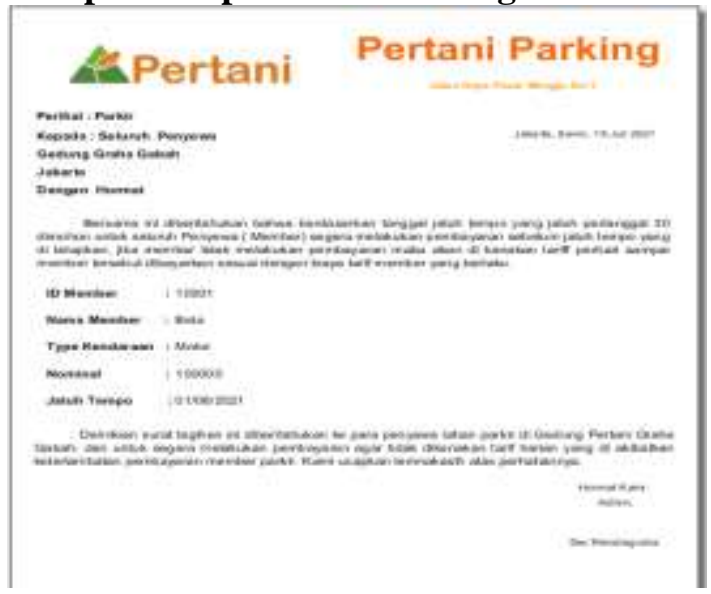

Gambar 18. Tampilan Laporan Data Penagihan

Pada tampilan ini menampilkan laporan penagihan member yang telah dicetak. 


\section{SIMPULAN DAN SARAN}

Peneliti memiliki simpulan dengan menggunakan sistem aplikasi ini berdasarkan rumusan masalah adalah Sistem aplikasi penagihan member parking pada Pertani Graha Gabah menggunakan bahasa program java dengan editor Netbeans 8.2. Data penagihan member parking tersimpan secara aman dengan menggunakan MySQL sebagai database. Dalam sistem aplikasi penagihan member parking, laporan-laporan yang dihasilkan berupa laporan pegawai, laporan member per orangan, laporan member perusahaan, laporan kartu member, laporan jenis kendaraan, serta tagihan member. Sistem aplikasi penagihan member parking pada Pertani Graha Gabah bisa meringankan pekerjaan admin serta memperbaiki pengelolaan data.

Saran dari penulis atas hasil penelitian yang di lakukan pada Pertani Graha Gabah maka penulis dapat memberi saran diantaranya sebelum aplikasi baru dilaksanakan, admin sebagai user perlu mendapat penjelasan dengan baik mengenai sistem aplikasi penagihan memnber parking pada Pertani Graha Gabah sehingga tidak terjadi kesalahan. Rancangan Sistem Aplikasi Penagihan Member parking pada Pertani Graha Gabah haruslah didukung oleh sistem yang disiplin dan peraturan yang baik sesuai ketetapan PT.Pertani Properti agar berjalan dengan semestinya. Pada penggunaan aplikasi ini admin sebagai pengguna harus teliti agar terhindar dari kesalahan dalam menginput karena sistem aplikasi ini berhubungan dengan data diri member.

4. Diharapkan kedepannya Pertani Parking dapat mengevaluasi apa saja hal yang dibutuhkan yang belum disediakan pada aplikasi ini, sehingga untuk kedepannya perlu adanya pengembangan, penambahan fitur dalam aplikasi agar lebih lengkap dan juga mempermudah setiap proses yang dibutuhkan PT. Pertani Properti.manu

\section{UCAPAN TERIMAKASIH}

Terima kasih penulis ucapkan untuk PT. Pertani Properti beserta jajarannya yang telah memberikan bantuan dan izin sehingga penelitian ini terlaksana dengan baik.
DAFTAR PUSTAKA

Ahmadi, R. (2014). Metodologi Penelitian Kualitatif. Yogyakarta.

Budiman, A., \& Triono, J. (2016). Sistem Informasi Parkir Kendaraan Bermotor Berbasis Android. Pilar Teknologi: Jurnal Ilmiah Ilmu-Ilmu Teknik, I(1), 42-49.

Enterprise, J. (2015). Mengenal Pemograman Database. PT Elex Media Komputindo.

Hidayat, R., \& Cheisviyanny, C. (2013). Pengaruh Kualitas Penetapan Pajak dan Tindakan Penagihan Aktif terhadap Pencairan Tunggakan Pajak. Jurnal WRA, 1(1), 1-20.

Ismunandar, A. R. N., Afrizal, T., \& Dwitiyanti, N. (2021). Aplikasi Penjualan Aksesoris Handphone Pada Asia Accessories Hp. Seminar Nasional Riset Dan Inovasi Teknologi (Semnas Ristek), 86-91.

Kurniawan, H., Eri, M., \& Nur, R. (2011). Aplikasi Inventory Menggunakan Java Netbeans, Xampp dan iReport. Elex Media Komputindo.

Ladjamudin, A.-B. Bin. (2013). Analisi dan Desain Sistem Informasi. Graha Ilmu.

Peraturan Daerah Provinsi Khusus Ibukota Jakarta. (2014). Peraturan Daerah Provinsi Ibukota Jakarta Nomor 5 Tahun 2014 Tentang Transportasi. In Transportasi (Transportation).

Rizky, S. (2011). Rekayasa Perangkat Lunak. Prestasi Pustaka.

Sadeli, M. (2014). Aplikasi Bisnis dengan PHP dan MySQL. Maxikom.

Sommerville, I. (2011). Software Engineering (Rekayasa Perangkat Lunak). Erlangga.

Sutabri, T. (2012). Analisis Sistem Informasi. Westriningsih. (2012). Panduan Aplikatif \& Solusi (PAS) Membangun Aplikasi Bisnis dengan Netbeans 7. Andi. 